\title{
TRIB1 downregulates hepatic lipogenesis and glycogenesis via multiple molecular interactions
}

\author{
Yuumi Ishizuka', Kazuhiro Nakayama', Ayumi Ogawa', Saho Makishima', \\ Supichaya Boonvisut', Atsushi Hirao ${ }^{2}$, Yusaku Iwasaki ${ }^{3}$, Toshihiko Yada ${ }^{3}$, \\ Yoshiko Yanagisawa ${ }^{1,4}$, Hiroshi Miyashita ${ }^{5}$, Masafumi Takahashi ${ }^{6}$, Sadahiko Iwamoto' \\ and Jichi Medical University Promotion Team of a Large-Scale Human Genome Bank \\ for All over Japan ${ }^{7}$ \\ 'Division of Human Genetics, Center for Molecular Medicine, Jichi Medical University, 3311-1 Yakushiji, Shimotsuke, \\ Tochigi 329-0498, Japan \\ ${ }^{2}$ Department of Anatomy ${ }^{3}$ Division of Integrative Physiology, Department of Physiology, Jichi Medical University, \\ Tochigi 329-0498, Japan \\ ${ }^{4}$ Health Care Food Research, Human Health Care Research, Research and Development, Kao Corporation, \\ Sumida-ku, Tokyo 131-8501, Japan \\ ${ }^{5}$ Jichi Medical University Health Care Center, Shimotsuke-shi, Tochigi 329-0498, Japan \\ ${ }^{6}$ Division of Inflammation Research, Center for Molecular Medicine, Jichi Medical University, \\ Tochigi 329-0498, Japan \\ ${ }^{7}$ Division of Community and Family Medicine, Center for Community Medicine, Jichi Medical University, \\ 3311-1 Yakushiji, Shimotsuke, Tochigi 329-0498, Japan
}

Correspondence should be addressed to S Iwamoto Email

siwamoto@jichi.ac.jp

\begin{abstract}
Mammalian tribbles homolog 1 (TRIB1) regulates hepatic lipogenesis and is genetically associated with plasma triglyceride (TG) levels and cholesterol, but the molecular mechanisms remain obscure. We explored these mechanisms in mouse livers transfected with a TRIB1 overexpression, a shRNA template or a control (LacZ) adenovirus vector. The overexpression of TRIB1 reduced, whereas induction of the shRNA template increased, plasma glucose, TG, and cholesterol and simultaneously hepatic TG and glycogen levels. The involvement of TRIB1 in hepatic lipid accumulation was supported by the findings of a human SNP association study. A TRIB1 SNP, rs6982502, was identified in an enhancer sequence, modulated enhancer activity in reporter gene assays, and was significantly $\left(P=9.39 \times 10^{-7}\right)$ associated with ultrasonographically diagnosed nonalcoholic fatty liver disease in a population of 5570 individuals. Transcriptome analyses of mouse livers revealed significant modulation of the gene sets involved in glycogenolysis and lipogenesis. Enforced TRIB1 expression abolished CCAAT/enhancer binding protein A (CEBPA), CEBPB, and MLXIPL proteins, whereas knockdown increased the protein level. Levels of TRIB1 expression simultaneously affected MKK4 (MAP2K4), MEK1 (MAP2K1), and ERK1/2 (MAPK1/3) protein levels and the phosphorylation of JNK, but not of ERK1/2. Pull-down and mammalian two-hybrid analyses revealed novel molecular interaction between TRIB1 and a hepatic lipogenic master regulator, MLXIPL. Co-expression of TRIB1 and CEBPA or MLXIPL reduced their protein levels and proteasome inhibitors attenuated the reduction. These data suggested that the modulation of TRIB1 expression affects hepatic lipogenesis and glycogenesis through multiple molecular interactions.
\end{abstract}

Journal of Molecular Endocrinology (2014) 52, 145-158 http://jme.endocrinology-journals.org DOI: $10.1530 / J M E-13-0243$
(C) 2014 Society for Endocrinology Printed in Great Britain
Published by Bioscientifica Ltd. 


\section{Introduction}

Plasma concentrations of lipids are a heritable risk factor for the development of atherosclerosis and related cardiovascular diseases (CVDs). High concentrations of LDL-associated cholesterol elevate the risk of ischemic heart disease and high concentrations of HDL-associated cholesterol reduce the risk (Law et al. 2003, Lewington et al. 2007). An increase in plasma triglyceride (TG) concentrations is also an independent risk factor for CVD (Bansal et al. 2007, Nordestgaard et al. 2007). The European genome-wide SNP association studies (GWAS) have associated 95 loci with blood lipid levels (Teslovich et al. 2010). The downstream linkage disequilibrium (LD) block of mammalian tribbles homolog 1 (TRIB1) is one locus that has convincing impact on CVD and levels of TG and LDL across several ethnic groups (Nakayama et al. 2009, Teslovich et al. 2010). A functional study using knockout mice and overexpression experiment has confirmed TRIB1 involvement in hepatic lipogenesis, which affects very low density lipoprotein (VLDL) production (Burkhardt et al. 2010). However, the molecular mechanisms remain unknown. Therefore, we explored the molecular pathways using a mouse model and functional variations in the LD block that affect levels of TRIB1 expression.

TRIB1, TRIB2, and TRIB3 share 45\% peptide sequence similarity and homology with tribbles (Hegedus et al. 2007), a Drosophila protein that inhibits mitosis during the early developmental stage by binding to the CDC25 homolog, string (Grosshans \& Wieschaus 2000). Genes in the Tribbles family encode a kinase-like domain but lack catalytic core motifs and kinase activities (Sung et al. 2006). A carboxy-terminal hexapeptide motif is shared among the three tribbles proteins and it is the binding site for E3 ubiquitin ligase constitutive photomorphogenic protein 1 (COP1) that participates in the proteasomemediated degradation of some targets of tribbles (Qi et al. 2006, Yokoyama \& Nakamura 2011). TRIB1-3 also provides a motif for MEK1 binding at near C-termini, which can enhance or inhibit MEK/MAPK signaling dependently on cell type and target molecule (Sung et al. 2006). The MEK1 binding domain is also involved in molecular interaction with CCAAT/enhancer binding proteins (CEBPA and CEBPB; Keeshan et al. 2006, Yokoyama et al. 2010). Furthermore, TRIB2 and TRIB3 interact with specific target molecules. Molecular interactions have been identified between TRIB3 and acetyl-coenzyme A carboxylase (Qi et al. 2006), Akt (Du et al. 2003), peroxisome proliferator-activated receptor $\gamma$ (PPAR $\gamma$; Takahashi et al. 2008), CEBP homologous protein (CHOP), and activating transcription factor 4 (ATF4; Ohoka et al. 2005). Fewer unique target molecules have been identified for TRIB1 than for TRIB3, among which factors involved in hepatic lipogenesis are likely to be included. Target molecules were searched using mouse models with TRIB1 overexpression or knockdown predominantly in the liver using an adenoviral gene delivery system.

\section{Experimental procedures}

\section{Adenovirus vector constructs}

The open reading frame (ORF) of TRIB1 cDNA under a CMV promoter (NM_025195, pAx-CMV-TRIB1) and a mouse Trib1 shRNA template (pAx-shTrib1; Supplementary Table 1 , see section on supplementary data given at the end of this article) were inserted into pAxcwit (Takara Bio, Inc., Otsu, Japan). The control was an adenovirus encoding LacZ, pAxCA-LacZ. Purified adenovirus vectors were titrated and $2.0 \times 10^{9} \mathrm{pfu}$ of adenoviruses were injected into the tail veins of mice.

\section{Animal experiments}

Male 12-week-old C57B16 mice (CLEA Japan, Inc., Tokyo, Japan) were housed in an air-conditioned environment with a $12 \mathrm{~h}$ light: $12 \mathrm{~h}$ darkness cycle. Blood samples were collected from the tail vein during the morning under conditions of food intake ad libitum or after $12 \mathrm{~h}$ of starvation. Plasma glucose was measured using Accu-Chek (Roche Diagnostics). Plasma TG, total cholesterol, and aspartate aminotransferase (AST) levels were measured using Fuji Dry Chem System (Fujifilm, Kanagawa, Japan). Plasma free fatty acid, $\beta$-hydroxybutyrate, and insulin levels were measured by NEFA C Kit (Wako, Osaka, Japan), fluorometric assay kit (Cayman Chemical Company, Ann Arbor, MI, USA), and ELISA system (Morinaga, Yokohama, Japan) respectively. Oxygen consumption $\left(\mathrm{VO}_{2}\right)$ and carbon dioxide production $\left(\mathrm{VCO}_{2}\right)$ were individually measured indirectly using an Oxymax V5.61 calorimeter (Columbus Instruments, Columbus, OH, USA). Locomotor activity was estimated using an ACTIMO-100 infrared activity monitoring system (Shinfactory, Fukuoka, Japan). The mice were killed at 4 or 8 days post-injection after $12 \mathrm{~h}$ of starvation. Liver TGs were

Published by Bioscientifica Ltd. 
extracted in chloroform:methanol $(2: 1, \mathrm{v} / \mathrm{v})$ and measured using commercial kits (Wako) (Rahman et al. 2007). Glycogens were extracted into 5\% trichloroacetic acid and quantified using phenol-sulfuric acid (Matsusue et al. 2004). Frozen sections of mouse liver were stained with hematoxylin and eosin (H\&E), Oil Red O, or PAS. Hepatocyte apoptosis was assessed using a colorimetric TUNEL System (Promega). Mice that had fasted for $12 \mathrm{~h}$ were injected with glucose $(1.8 \mathrm{~g} / \mathrm{kg})$ or insulin $(1 \mathrm{U} / \mathrm{kg})$ i.p. for glucose tolerance test (GTT) and insulin tolerance test (ITT) respectively. The Animal Care and Use Committee of Jichi Medical University approved all procedures involving animals.

\section{Expression profiling}

Hepatic total RNA was extracted immediately after killing. Expression was profiled by hybridization to an Affimetrix Mouse 430_2 oligonucleotide microarray chip. Pathways that were significantly enhanced or reduced by altered TRIB1 expression were searched using Gene Set Enrichment Analysis (GSEA) Software provided by the Broad Institute (http://www.broad.mit.edu/gesa/) and the Kyoto Encyclopedia of Genes and Genomes database. The accuracy of the expression levels of individual genes in the microarray were confirmed by quantitative RT-PCR using the primers listed in Supplementary Table 1. Hepatic protein $(20 \mu \mathrm{g})$ was separated by electrophoresis in $10 \%$ SDS-PAGE gels and candidate TRIB1 target proteins were measured by western blotting using the specific primary antibodies CEBPA, NFkB p65, SREBP1 (against both of SREBP1a and 1c precursor), p-JNK, JNK and $\beta$-actin (Santa Cruz), CEBPB and MLXIPL (Abcam, Cambridge, UK), MEK1 (Epitomics, Burlingame, CA, USA), MKK4 and ERK1/ERK2 (R\&D Systems, Minneapolis, MN, USA), and p-ERK1/ERK2 (Abnova, Taipei, Taiwan).

\section{Assays of molecular interactions}

TRIB1 target protein interaction was assessed using the mammalian two-hybrid and HaloTag mammalian PullDown systems (Promega). Full-length TRIB1 cDNAs or TRIB1 cDNAs with deleted N-terminal 90 residues $(\Delta \mathrm{N} 90)$ and pseudocatalytic loop $(\triangle \mathrm{PCL}), \mathrm{COP} 1(\triangle \mathrm{COP})$, or MEK $(\triangle \mathrm{MEK})$ binding domains were inserted into the pBIND vector to generate GAL4-fusion proteins. The ORFs of CEBPA (NM_004364.2), CEBPB (NM_005194.2), and MLX interacting protein-like (MLXIPL, NM_032951.2) were inserted into the pACT vector to generate VP16-fusion proteins. VP16-MLXIPL constructs with a deleted nuclear localization signal ( $\Delta$ NLS; residues 159-183; Fukasawa et al. 2010) and basic helix-loop-helix zipper ( $\triangle \mathrm{bHLH}$; residue 648-724; Li et al. 2006) or leucine-zipper-like ( $\Delta$ ZIP; residue 792-837; de Luis et al. 2000) domains were also prepared to search for the interacting domain(s). These constructs were co-transfected using Lipofectamine 2000 (Life Technologies) into COS7 cells harboring the pGL4.31 vector. Empty pBIND and pACT vectors served as negative controls. Firefly reporter expression was measured $48 \mathrm{~h}$ later against Renilla luciferase encoded by the pBIND vector. Constructs were co-transfected into COS7 cells and molecular interactions were assessed as relative luciferase activities. The ORFs of TRIB1, CEBPA, and MLXIPL were inserted into the $\mathrm{pHTN}$ vector or $\mathrm{PCR} 3$ vector with an influenza hemagglutinin (HA)-tag for pull-down assays. Constructs were co-transfected into COS7 cells and then HaloTag fusion and associated proteins were extracted from cell lysates using HaloLink resin. Molecular interactions were compared by western blotting with anti-TRIB1 (Abgent, San Diego, CA, USA) and anti-HA (Sigma-Aldrich) antibodies to the empty pHTN vector as the negative control. Proteasomemediated degradation of CEBPA or MLXIPL was examined by co-transfection in COS7 cells with TRIB1 in pCR3 vectors with or without an inhibitor of the proteasome system ( $1 \mu \mathrm{M}$ epoxomicin or $10 \mu \mathrm{M}$ MG132 (Sigma)). Cells were harvested $16 \mathrm{~h}$ later and the protein levels were measured by western blotting.

\section{Survey of functional SNP in the downstream sequence of TRIB1}

The upstream sequence of the TRIB1 gene from -1336 to -1 relative to the ATG start codon was subcloned into the pGL3 basic vector and used as the promoter vector. We selected six conserved sequences in the $25 \mathrm{~kb}$ LD block downstream of TRIB1, through a database search at ENCODE (ENCODE Project Consortium et al. 2011, http://genome.ucsc.edu/ENCODE/) and HapMap (http:// hapmap.ncbi.nlm.nih.gov/) (Supplementary Fig. 4, see section on supplementary data given at the end of this article). Fragments were amplified from several individuals and subcloned into the Sall site of the pGL3-TRIB1 promoter vector. Constructs encoding SNP variations were verified by sequencing and transfected into HepG2 cells along with the pRL vector (Renilla Luciferase; Promega). Forty-eight hours later, the relative light units (firefly/Renilla light units) were measured using a dual luciferase reporter assay system (Promega) and a TD-20/20 luminometer (Turner Designs, Sunnyvale, CA, USA).

Published by Bioscientifica Ltd. 
SNP association studies between TRIB1 with non-alcoholic fatty liver disease

The first association study comprised 3013 participants, recruited from outpatients whose general health was assessed at Jichi Medical University Hospital. The second population comprised samples whose hepatic ultrasonographic information was extracted from a database of 21004 Japanese individuals (Nakayama et al. 2009). Experienced clinical technologists performed hepatic ultrasonography under the guidance of clinicians who reviewed photocopies of the scans. We excluded participants with known liver diseases or those who consumed $>20 \mathrm{~g} /$ day of alcohol. The Ethics Committee at Jichi Medical University approved the study protocol and all recruits provided written informed consent to participate. The genotypes of rs6982502, rs17321515, and rs2980867 were determined using the TaqMan system. The effects of the risk allele on nonalcoholic fatty liver disease (NAFLD) and log-transformed plasma TG were assessed by logistic regression models and multiple regression analysis assuming an additive model of inheritance respectively. Age, sex, BMI, and a clinical history of diabetes were included in both models. Data were statistically analyzed using SPSS 11.0 (SPSS Japan).

\section{Results}

\section{Overexpression and knockdown of TRIB1 influenced multiple metabolic parameters in mice}

We determined whether variable expression levels of TRIB1 affect hepatic lipid storage using an adenoviral gene delivery system to modulate TRIB1 expression in the mouse liver. X-gal staining of mouse organs injected with pAxCA-LacZ validated nearly exclusive hepatic induction of the adenovirus vector system. The expression of TRIB1 protein that was above physiological levels on day 4 after pAx-CMV-TRIB1 injection (Supplementary Fig. 1A, see section on supplementary data given at the end of this article) became almost equivalent to the level of internal TRIB1 in the control by day 8 . However, reduction of the TRIB1 protein level from days 4 to $8(-98 \%)$ was inconsistent with that of the transcript level $(-89 \%)$ (Supplementary Fig. 1B), suggesting post-translational negative regulation of TRIB1. The knockdown vector, pAx-shTrib1, reduced the protein and mRNA levels to about $60-80 \%$ of the control vector without affecting Trib2 and Trib3 expression (Supplementary Fig. 1A, C and D). The enforced expression and knockdown of TRIB1 significantly decreased and increased plasma TG levels in mice fed ad libitum respectively (Table 1), while the difference in TG levels between knockdown and control mice at day 4 failed to achieve statistical significance. Plasma TG levels in starved mice did not significantly differ. Total cholesterol levels were also decreased and increased by TRIB1 overexpression and knockdown at day 8 respectively. The overexpression of TRIB1 notably decreased, whereas its knockdown increased plasma glucose levels but did not significantly affect insulin levels. The body weight and epididymal fat pads of mice overexpressing TRIB1 were significantly decreased, although food intake, locomotor activity, and $\mathrm{O}_{2}$ consumption were equivalent to those of mice harboring the control vector (Table 1, Fig. 1A, and Supplementary Fig. 2, see section on supplementary data given at the end of this article). The respiratory exchange ratio (RER) was significantly repressed by TRIB1 overexpression (Fig. 1A and Supplementary Fig. 2). Increased $\beta$-hydroxybutyrate (Table 1) and repressed RER simultaneously suggested relatively decreased carbohydrate consumption and increased lipid $\beta$-oxidation in mice overexpressing TRIB1. Knockdown of Trib1 increased the glucose level at the late phase of GTT (Fig. 1B), while the glucose level in ITT fell essentially to control levels (Fig. 1C), suggesting that hepatic knockdown of Trib1 impaired glucose tolerance but not systemic insulin sensitivity. Baseline glucose levels of the mice tested GTT and ITT were not equivalent to the data of simple blood collection under fasting, probably due to their diversified nutritional and sampling condition. The knockdown of TRIB1 expression increased hepatic lipid droplets and PAS-stained material at day 8 (Fig. 1D), which reflected the 160 and $166 \%$ increases in TG and glycogen levels in the extracts respectively (Fig. 1E and F). In contrast, TRIB1 overexpression decreased TG and glycogen by 29 and $98 \%$ respectively. Leukocyte infiltration of the liver under conditions of enforced Trib1 expression was remarkable at day 8 (Fig. 1D). Leukocytes were barely detectable at day 4 , but the number of TUNEL-positive hepatocytes was significantly increased in mice overexpressing TRIB1 (Fig. 1D and G). Hepatocyte destruction might have resulted in the remarkably increased plasma AST level of TRIB1 overexpression (Table 1). The relatively mild AST increase in mice with TRIB1 knockdown and those injected with the LacZ vector might have resulted from inflammation induced by adenovirus.

\section{Pathway analysis using hepatic transcriptome}

We assessed the expression profiles of total RNA in mouse livers at 4 and 8 days after adenovirus injection using

Published by Bioscientifica Ltd. 
Table 1 Blood parameters and tissue weight of mice injected with AV. Values are mean \pm S.E.M. of seven to eight animals. Blood samples were drawn from tail vein under ad libitum feeding (Fed) or 12-h fasting (Fasting) at ZTO or ZT12 respectively. Killing of the animals was performed after $12-\mathrm{h}$ fasting at the indicated date from the administration of $\mathrm{AV}$ vectors

\begin{tabular}{|c|c|c|c|c|c|}
\hline \multirow{3}{*}{ Day 4} & \multirow[b]{2}{*}{ sh } & \multirow[b]{2}{*}{ LacZ } & \multirow[b]{2}{*}{ TRIB1 } & \multicolumn{2}{|c|}{ t-test } \\
\hline & & & & sh vs LacZ & LacZ vs TRIB1 \\
\hline & & & & & \\
\hline Change of body weight (g) & $0.05 \pm 0.32$ & $0.07 \pm 0.37$ & $-1.52 \pm 0.49$ & NS & $<0.01$ \\
\hline \multirow{2}{*}{\multicolumn{6}{|c|}{$\begin{array}{l}\text { Food intake (g/day) } \\
\text { Plasma glucose }(\mathrm{mg} / \mathrm{dl})\end{array}$}} \\
\hline & & & & & \\
\hline Fed & $236.9 \pm 26.9$ & $223.8 \pm 23.9$ & $126.4 \pm 23.9$ & NS & $<0.01$ \\
\hline Fasting & $196.0 \pm 33.9$ & $172.8 \pm 25.6$ & $95.0 \pm 19.1$ & NS & $<0.01$ \\
\hline \multicolumn{6}{|l|}{ Plasma triglyceride (mg/dl) } \\
\hline Fed & $95.0 \pm 9.6$ & $93.8 \pm 19.2$ & $22.0 \pm 8.0$ & NS & $<0.01$ \\
\hline Fasting & $27.8 \pm 2.8$ & $28.0 \pm 5.7$ & $30.8 \pm 3.8$ & NS & NS \\
\hline \multicolumn{6}{|l|}{ Total cholesterol (mg/dl) } \\
\hline Fed & $70.0 \pm 13.1$ & $58.0 \pm 8.7$ & $67.7 \pm 3.5$ & NS & NS \\
\hline Fasting & $66.5 \pm 9.8$ & $50.7 \pm 6.8$ & $40.7 \pm 5.9$ & NS & NS \\
\hline \multicolumn{6}{|l|}{ Free fatty acid (mEq/l) } \\
\hline Fed & $0.47 \pm 0.10$ & $0.58 \pm 0.19$ & $0.54 \pm 0.14$ & NS & NS \\
\hline Fasting & $0.58 \pm 0.02$ & $0.66 \pm 0.19$ & $0.55 \pm 0.23$ & NS & NS \\
\hline \multicolumn{6}{|l|}{$\beta$-Hydroxybutyrate $(\mu \mathrm{mol} / \mathrm{l})$} \\
\hline Fasting & $84.5 \pm 13.5$ & $79.6 \pm 28.2$ & $124.5 \pm 16.5$ & NS & $<0.05$ \\
\hline \multicolumn{6}{|l|}{ AST (unit/l) } \\
\hline Epididymal fat pad ${ }^{a}$ & $1.31 \pm 0.14$ & $1.27 \pm 0.19$ & $0.89 \pm 0.29$ & NS & $<0.01$ \\
\hline \multicolumn{6}{|l|}{ Insulin (ng/ml) } \\
\hline Fed & $0.19 \pm 0.18$ & $0.21 \pm 0.18$ & $0.16 \pm 0.12$ & NS & NS \\
\hline Fasting & $0.32 \pm 0.16$ & $0.67 \pm 0.23$ & $0.22 \pm 0.18$ & NS & NS \\
\hline \multicolumn{6}{|l|}{ Day 8} \\
\hline Change of body weight (g) & $0.46 \pm 0.40$ & $0.175 \pm 0.31$ & $-2.34 \pm 0.52$ & NS & $<0.01$ \\
\hline Food intake (g/day) & $2.59 \pm 0.15$ & $2.46 \pm 0.28$ & $2.39 \pm 0.12$ & NS & NS \\
\hline \multicolumn{6}{|l|}{ Plasma glucose (mg/dl) } \\
\hline Fed & $240.8 \pm 4.8$ & $198.8 \pm 29.4$ & $118.0 \pm 4.3$ & $<0.01$ & $<0.01$ \\
\hline Fasting & $154.8 \pm 29.1$ & $154.3 \pm 26.2$ & $88.3 \pm 10.7$ & NS & $<0.01$ \\
\hline \multicolumn{6}{|l|}{ Plasma triglyceride $(\mathrm{mg} / \mathrm{dl})$} \\
\hline Fed & $123.3 \pm 22.9$ & $95.3 \pm 21.6$ & $49.3 \pm 14.1$ & $<0.05$ & $<0.01$ \\
\hline Fasting & $39.5 \pm 7.2$ & $47.0 \pm 6.5$ & $41.8 \pm 9.6$ & NS & NS \\
\hline \multicolumn{6}{|l|}{ Total cholesterol (mg/dl) } \\
\hline Fed & $91.8 \pm 3.6$ & $82.3 \pm 12.2$ & $48.5 \pm 12.4$ & $<0.05$ & $<0.01$ \\
\hline Fasting & $54.0 \pm 2.6$ & $51.3 \pm 6.0$ & $37.3 \pm 5.0$ & NS & $<0.01$ \\
\hline \multicolumn{6}{|l|}{ Free fatty acid (mEq/l) } \\
\hline Fed & $0.53 \pm 0.02$ & $0.49 \pm 0.02$ & $0.487 \pm 0.07$ & NS & NS \\
\hline Fasting & $0.77 \pm 0.27$ & $0.65 \pm 0.10$ & $0.871 \pm 0.37$ & NS & NS \\
\hline \multicolumn{6}{|l|}{$\beta$-Hydroxybutyrate $(\mu \mathrm{mol} / \mathrm{l})$} \\
\hline Fasting & $99.7 \pm 36.5$ & $123.8 \pm 47.9$ & $257.6 \pm 61.8$ & NS & $<0.05$ \\
\hline \multicolumn{6}{|l|}{ AST (unit/l) } \\
\hline Fasting & $97.7 \pm 28.1$ & $346.8 \pm 68.0$ & $509.3 \pm 85.4$ & $<0.01$ & $<0.01$ \\
\hline Epididymal fat pad ${ }^{\mathrm{a}}$ & $1.11 \pm 0.04$ & $0.95 \pm 0.14$ & $0.66 \pm 0.05$ & NS & $<0.01$ \\
\hline \multicolumn{6}{|l|}{ Insulin (ng/ml) } \\
\hline Fed & $0.27 \pm 0.35$ & $0.57 \pm 0.66$ & $0.79 \pm 0.28$ & NS & NS \\
\hline Fasting & $0.50 \pm 0.52$ & $0.51 \pm 0.44$ & $0.16 \pm 0.31$ & NS & NS \\
\hline
\end{tabular}

NS, not significant.

aPercent of body weight.

microarrays to investigate how TRIB1 modulates hepatic lipid and glycogen storage. The number of genes with over a twofold difference in expression between the overexpression and knockdown groups numbered 2556 and 2158 at days 4 and 8 respectively and 1372 of these genes were shared. We compared pAx-CMV-TRIB1 with
pAxCA-LacZ and pAxCA-LacZ with pAx-shTrib1 at days 4 and 8 using GSEA. The commonly (3/4) enriched gene sets were regarded as significantly affected pathways. Fortyfive gene sets were commonly enriched by TRIB1 expression (Supplementary Table 2A, see section on supplementary data given at the end of this article). 
A
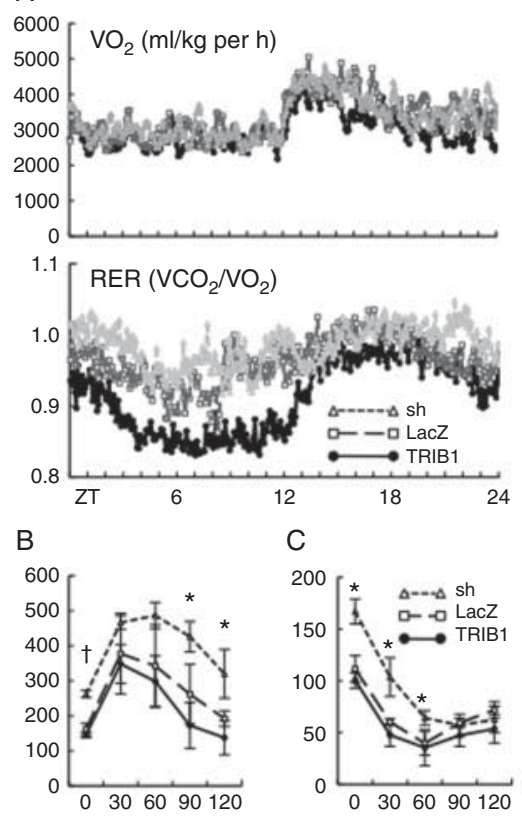

C

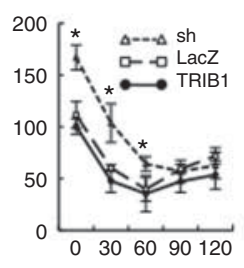

D
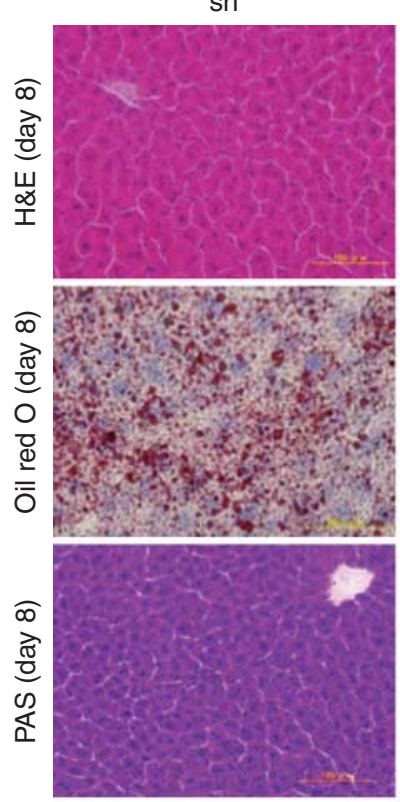
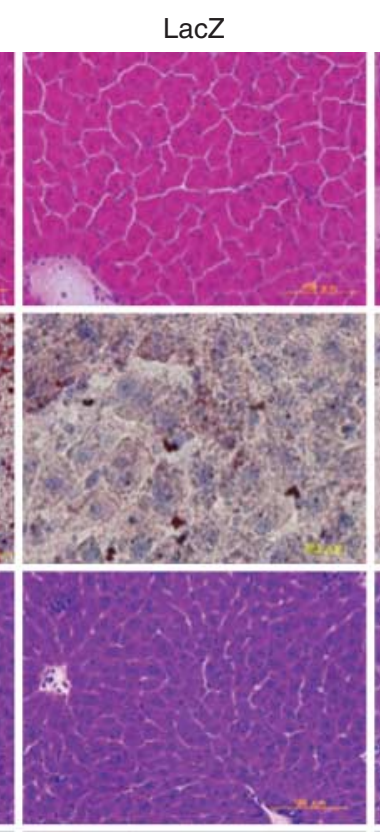
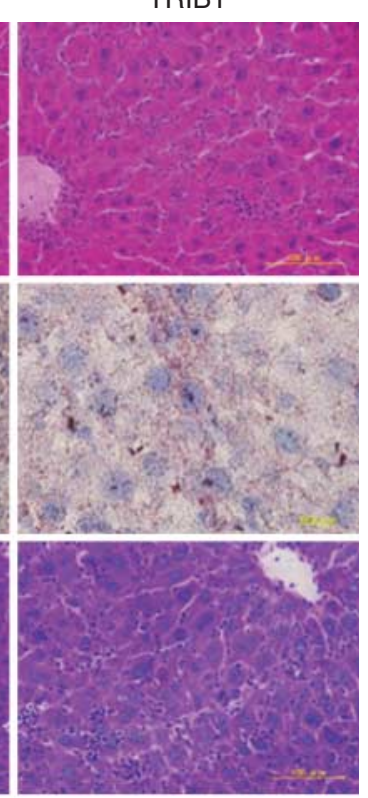
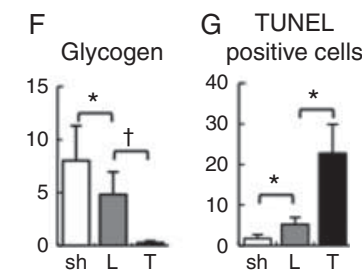
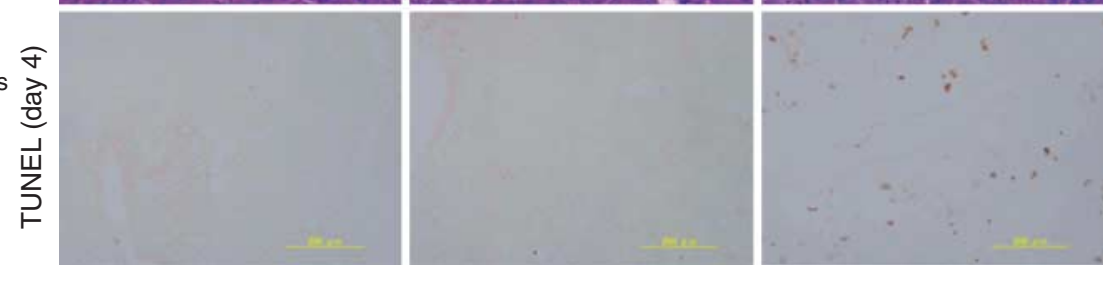

\section{Figure 1}

Effects of modulating TRIB1 expression on glucose, energy metabolism, liver histology, liver triglyceride (TG), and glycogen storage. (A) Average values of oxygen consumption $\left(\mathrm{VO}_{2}, \mathrm{ml} / \mathrm{kg}\right.$ per $\left.\mathrm{h}\right)$ and respiratory exchange ratios ( $\mathrm{RER}, \mathrm{VCO}_{2} / \mathrm{VO}_{2}$ ) at day 4 . Data were collected for $1 \mathrm{~min}$ at 5 -min intervals. The start of the light period was regarded as Zeitgeber time 0 (ZTO). (B) Glucose tolerance test. Average glucose values (mg/dl) of seven mice per vector (day 8 after vector administration) are shown. (C) Insulin tolerance test. ${ }^{*} P<0.05$ and ${ }^{\dagger} P<0.01$ (Student's $t$-test compared with results using $p A x C A-L a c Z$ and $p A x$-shTrib1 vectors). (D) Representative $H \& E$,

Although 12 of the enriched gene sets were associated with pathways involved in immune responses, nine gene sets were associated with nutrient metabolism. The expression heat map for starch and sucrose metabolism showed that TRIB1 overexpression enriched the genes involved in glycogenolysis and suppressed those involved in glycogen synthesis. The heat map for glycolysis and gluconeogenesis showed that the enrichment and depletion of genes (other than Pklr) involved in glycolysis and gluconeogenesis respectively (Supplementary Fig. 3A and B, see section on supplementary data given at the end of this article, and Fig. 2A). The overexpression of TRIB1 enriched the gene set for the insulin signaling pathway whereas knockdown enriched that for maturity onset diabetes (Supplementary
Oil Red O, PAS staining (day 8), and TUNEL study (day 4) of mouse liver injected with adenoviral vectors. Scale bars indicate $100 \mu \mathrm{m}$. (E) TG (mg/g) and $(F)$ glycogen $(\mu \mathrm{g} / \mathrm{g}$ ) contents in liver at starvation. (G) TUNEL-positive cells in liver section ( $n / f i e l d)$. Data are presented as means \pm s.D. $(n=7$ per adenoviral vector). LacZ, control vector encoding LacZ (pAxCA-LacZ); sh, knockdown vector encoding shRNA template (pAx-shTrib1); and TRIB1, overexpression vector ( $\mathrm{pAx}-\mathrm{CMV}$-TRIB1). ${ }^{*} P<0.05$ and ${ }^{\dagger} P<0.01$ (Student's $t$-test; significant change by pAx-shTrib1 vs pAxCA-LacZ or pAxCA-LacZ vs pAx-CMV-TRIB1).

Fig. 3C, D and E, and Supplementary Table 2B). These results are consistent with the low blood glucose levels and reduced glycogen storage identified in mice overexpressing TRIB1. Although GSEA did not appear to alter the pathways of fatty acid biosynthesis and oxidation (possibly due to the small number of genes involved in the pathway), TRIB1 overexpression downregulated, and knockdown increased the expression of genes involved in TG biosynthesis ( $S c d 1$, Elovl3, Elovl6, Gpat2, and Dgat2) and Acc1 and Fasn were downregulated by TRIB1 overexpression at day 4, which was confirmed by real-time PCR (Fig. 2B). However, four (Acc1, Fasn, Scd1, and Gpat2) became equivalent at day 8 . The expression levels of the genes for fatty acid oxidation (Acox1, Echs, Ehhadh, and Cpt1a) were inconsistent with the

Published by Bioscientifica Ltd 
A
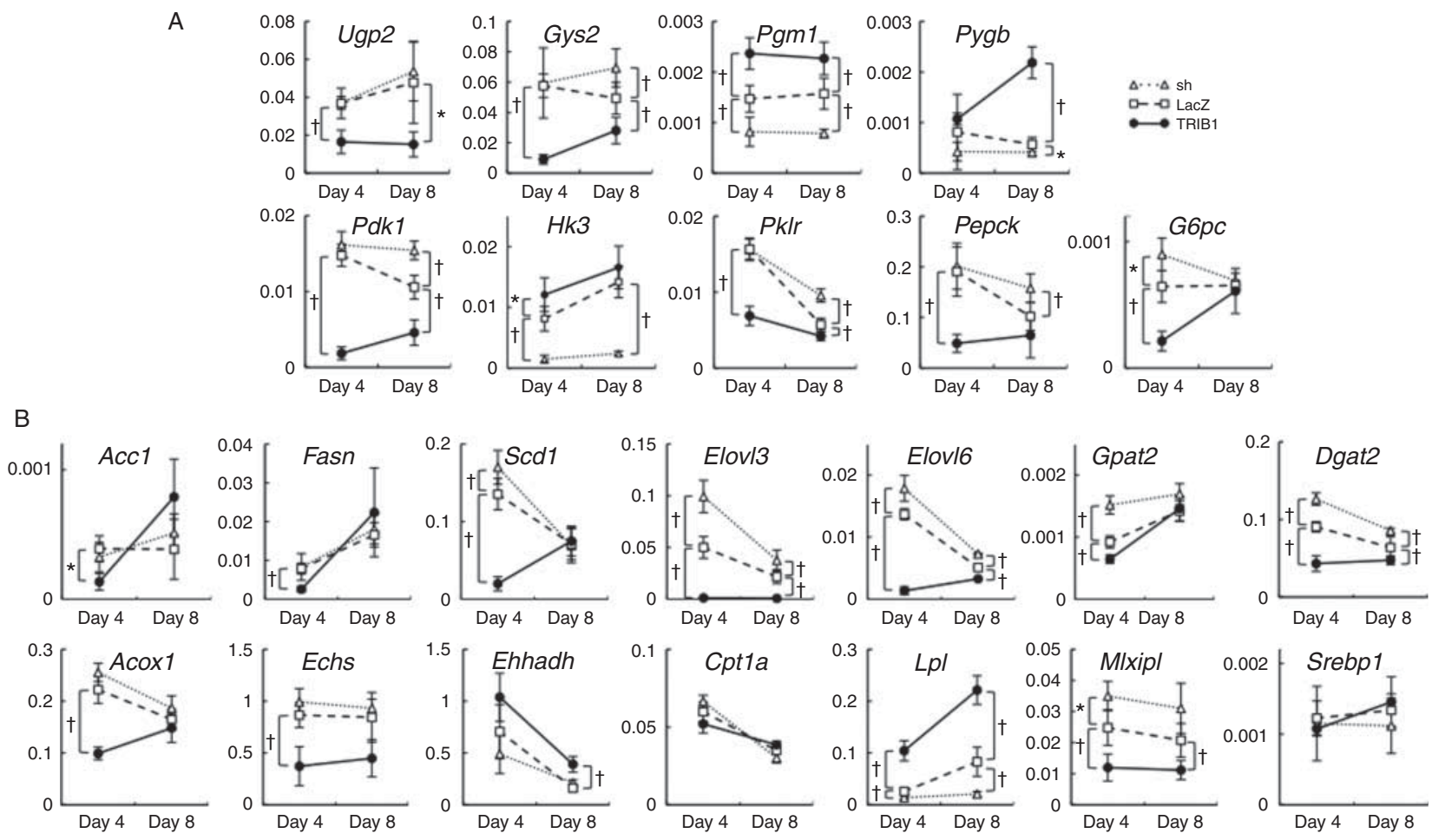

Figure 2

Expression levels of mRNA involved in glucose-glycogen (A) and lipid (B) metabolism quantified by real-time PCR analysis in the adenovirus-injected liver. $Y$-axis values show relative expression levels of respective genes

lipid levels. Among the transcription factors involved in lipogenesis, Mlxipl expression was significantly increased by knockdown and decreased by TRIB1 overexpression, but levels of Srebp1 transcripts did not change (Fig. 2B).

\section{Western blotting of potential targets of TRIB1}

TRIB1 interacts with COP1, CEBPA, CEBPB, MEK1, p65/RelA, and MKK4 (Hegedus et al. 2007). Levels of CEBPA and CEBPB were significantly decreased in the liver overexpressing TRIB1 and increased by knockdown (Fig. 3A). TRIB1 overexpression increased and decreased MEK1 (MAP2K1) by days 4 and 8 respectively and increased protein levels of MKK4 (MAP2K4) (Fig. 3B). Although MKK4 are scaffold activators of JNK, TRIB1 overexpression, and knockdown did not influence their protein levels, but overexpression downregulated the phosphorylation of 183/185Tyr (Fig. 3B). Erk protein levels were significantly increased by TRIB1 overexpression and decreased by knockdown, while phosphorylation was not influenced (Fig. 3B). Multiple changes in the transcript levels involved in TG synthesis suggested modulation of the hepatic lipogenic master regulators, against housekeeping gene, $36 \mathrm{~b} 4$. Data represent means \pm s.D. $(n=7$ per adenoviral vector). ${ }^{\star} P<0.05$ and ${ }^{\dagger} P<0.01$ (Student's $t$-test).

SREBP1 and MLXIPL. Enforced TRIB1 expression abolished MLXIPL protein on both days 4 and 8, whereas knockdown increased the protein level to 4.8 - and 4.9-fold that of control on days 4 and 8 respectively (Fig. 3A). While TRIB1 expression level did not influence levels of Srebp1 mRNA, protein levels were increased by TRIB1 overexpression and decreased by knockdown at day 8 (Fig. 3A), indicating that the change in the SREBP1 protein level was a compensatory phenomenon against the exhaustion of hepatic lipid content, which might have resulted in the partial recovery of transcript levels of TG synthetic genes.

\section{Molecular interaction between TRIB1 and MLXIPL}

We examined whether the disappearance of MLXIPL caused by TRIB1 overexpression resulted from their molecular interaction using mammalian two-hybrid and pull-down assays. Interaction between GAL4-TRIB1 and VP16-MLXIPL fusion proteins significantly enhanced reporter gene expression as did interactions with VP16CEBPA and VP16-CEBPB (Fig. 4C). The interaction with MLXIPL was attenuated by deletion of the NLS or the

Published by Bioscientifica Ltd. 
A

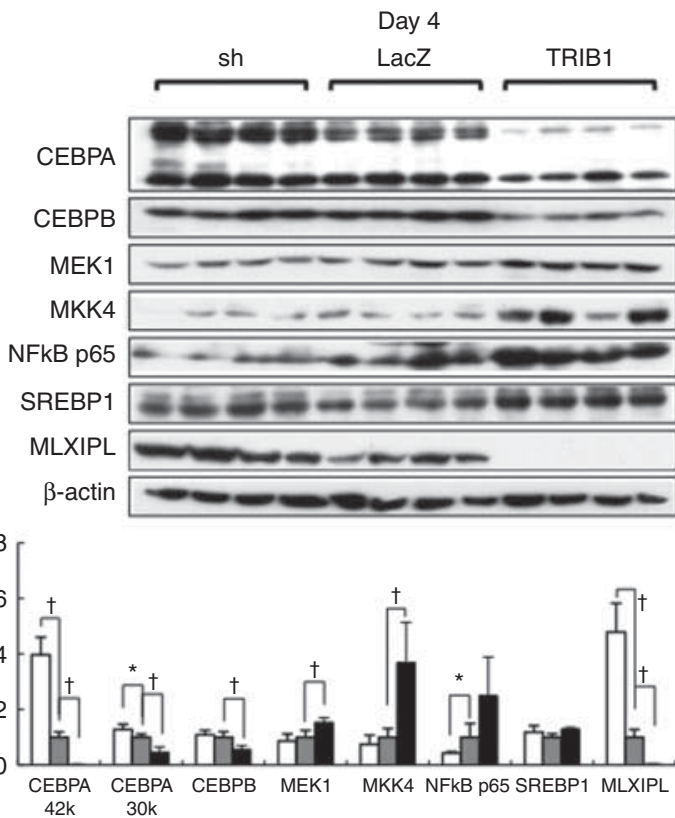

B

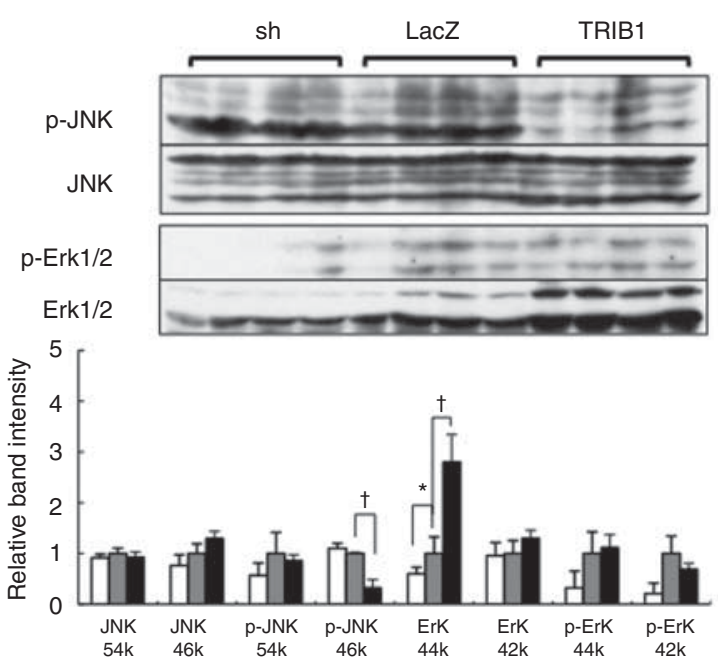

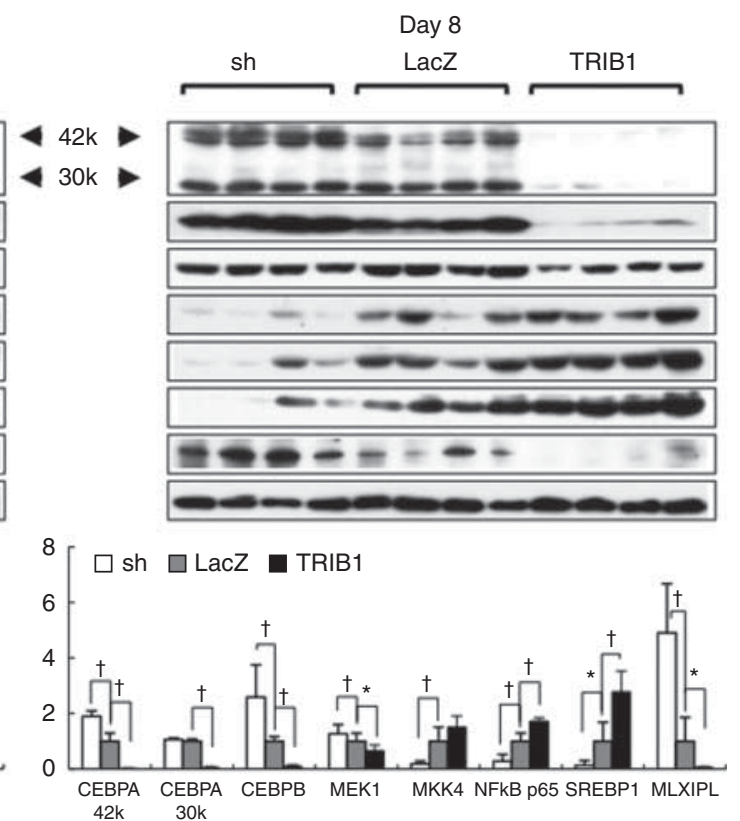
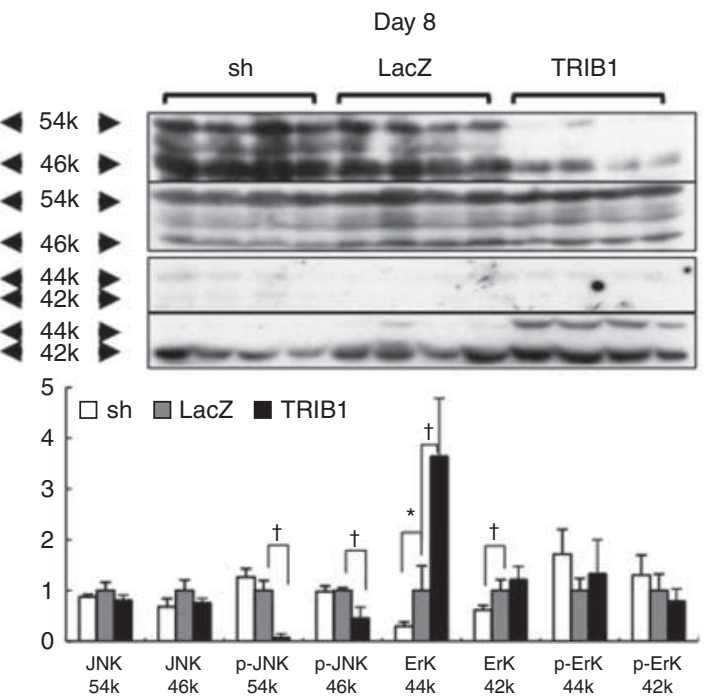

Figure 3

Effects of modulation of TRIB1 expression on target proteins. (A) Western blots. Hepatic protein $(20 \mu \mathrm{g})$ resolved by electrophoresis was transferred onto PVDF membranes and immunoblotted with respective primary antibodies against CEBPA, CEBPB, MEK1, MKK4, NFkB p65, SREBP1, MLXIPL, and $\beta$-actin. (B) Effects of modulation of TRIB1 expression on phosphorylation of proteins in MAPK cascade. Western blotting using

bHLH domain and disappeared in the absence of a ZIP domain (Fig. 4A and C). The interaction also disappeared when the pseudocatalytic loop or MEK1 binding domain of TRIB1 was removed from the VP16 fusion proteins and became significantly attenuated by deleting the COP1 binding domain (Fig. 4B and D). We tested mutual co-precipitation using HaloTag fusion proteins to verify antibodies against p-JNK, JNK, p-ERK1/ERK2, and ERK1/ERK2. Signals were quantified by densitometry and normalized to $\beta$-actin levels. Bar graphs show relative amounts of respective band intensities (means \pm s.D.; $n=7$ ). Control values (pAxCA-LacZ) are defined as $1 .{ }^{*} P<0.05$ and ${ }^{\dagger} P<0.01$ (Student's $t$-test)

interaction between TRIB1 and MLXIPL. Halo-CEBPA and halo-MLXIPL co-precipitated TRIB1 proteins, and, conversely, halo-TRIB1 co-precipitated CEBPA and MLXIPL (Fig. 4E). We then examined the involvement of the proteasome system in the regulation of CEBPA and MLXIPL protein levels through interaction with TRIB1. Co-expression with TRIB1 remarkably reduced CEBPA or

Published by Bioscientifica Ltd. 
A MLXIPL
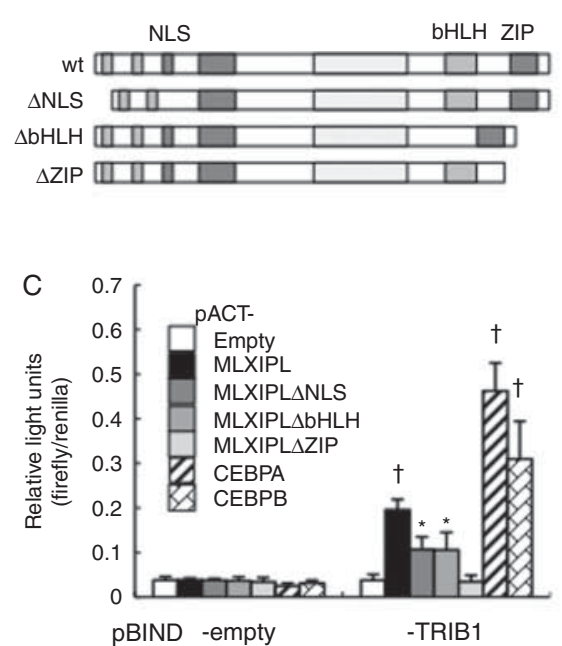

E

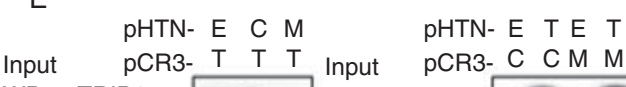
WB: $\alpha$-TRIB1 WB: $\alpha$-TRIB1

Input

WB: $\alpha$-CEBPA $\alpha-M L X I P L$

Pull-down WB: $\alpha$-TRIB1
B
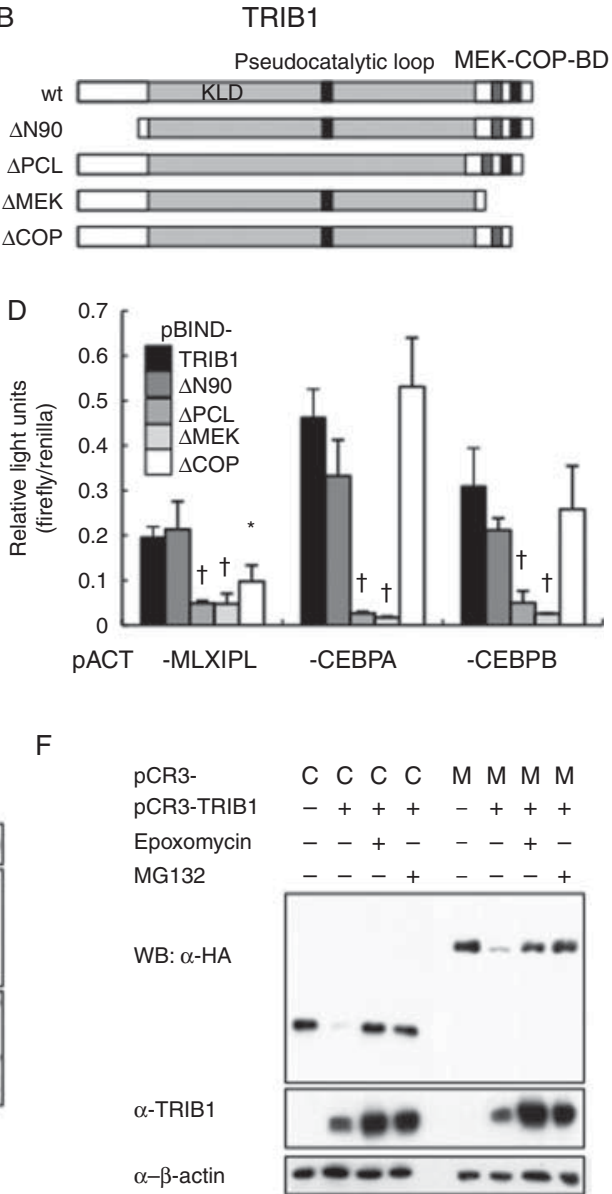

Figure 4

Studies of molecular interaction of TRIB1 with CEBPA, CEBPB, and MLXIPL. Constructs of MLXIPL mutants. NLS, nuclear localization signal; bHLH, basic helix-loop-helix zipper domain; and ZIP, leucine-zipper-like domain.

(B) Constructs of TRIB1 mutants. BD, binding domain and PCL, pseudocatalytic loop. (C) Mammalian two-hybrid assay. Vectors pBIND-empty or pBIND-TRIB1 were co-transfected with indicated pACT vectors into COS7 cells harboring pGL4.31 vector. Values are relative light units (firefly/Renilla, means \pm s.D.) of independent experiments in quadruplicate. $* P<0.05$ and ${ }^{\dagger} P<0.01$ (Student's $t$-test; $P A C T$ vs $P A C T$-empty and pBINDTRIB1 vectors). (D) Full-length TRIB1 CDNAs or TRIB1 CDNAs with deleted $\mathrm{N}$-terminal 90 residues $(\triangle \mathrm{N} 90)$, pseudo-catalytic loop $(\triangle \mathrm{PCL}), \mathrm{COP} 1(\triangle \mathrm{COP})$, or MEK ( $\triangle \mathrm{MEK}$ ) binding domains were co-transfected with PACT-MLXIPL,

MLXIPL protein levels and preoteasome inhibitors rescued CEBPA and MLXIPL from the reduction (Fig. 4F). The proteasome inhibitors simultaneously increased TRIB1 protein levels. These results indicated that molecular interactions between TRIB1 and CEBPA as well as MLXIPL accelerate their decay, and interaction of TRIB1 with the target proteins accelerated the decay of itself. Accelerated decay of TRIB1 may potentially explain the continuously repressed MLXIPL until day 8 of TRIB1 overexpression mice, while TRIB1 protein levels greatly reduced to nearly
CEBPA, or CEBPB vector. ${ }^{*} P<0.05$ and ${ }^{\dagger} P<0.01$; significant reduction compared with pBIND-TRIB1. (E) Pull-down assays. ORFs of TRIB1 (T), CEBPA (C), and MLXIPL (M) were inserted into PHTN vector or $\mathrm{PCR} 3$ vector with influenza hemagglutinin (HA)-tag. Negative control was empty pHTN (E) vector. Constructs were co-transfected into COS7 cells and then HaloTag fusion and associated proteins were extracted from cell lysates using HaloLink resin. Molecular interactions were assessed by western blotting using anti-TRIB1 or anti-HA antibodies (pull-down). (F) TRIB1 induced degradation of CEBPA and MLXIPL. COS7 cells were transfected with $p C R 3-$ HA-CEBPA (A) or -MLXIPL (M) along with pCR3-TRIB1 (+) or pCR3-empty $(-)$ vector with or without proteasome inhibitor (epoxomicin or MG132). Protein levels were assessed by western blotting.

physiological levels under still excessive human TRIB1 mRNA levels (Supplementary Fig. 1A and B).

\section{Identification of regulatory elements and SNP in the downstream of TRIB1}

To investigate whether the LD block at the downstream of TRIB1 encodes regulatory elements and whether variations in the sequence affect the regulatory function, we constructed luciferase reporter vectors that individually

Published by Bioscientifica Ltd. 
encoded six conservative fragments and the variants of high frequent SNPs (Fig. 5A). Whereas none of the constructs exhibited any enhancement activities in 293 and COS7 cells (not shown), fragment $1(+34834$ to 36 474; relative distance from 1st ATG of TRIB1) showed 5.2- and 4.4-fold enhanced activities in HepG2 cells (Fig. 5A). The allelic difference in the activities was statistically significant. Fragments 2, 3, 5, and 6 did not exhibit either enhancing activities or allelic differences in HepG2 cells. Fragment 4 showed weak (1.31 and 1.34) activities but the difference in rs2980867 variation was not statistically significant. Our cloned fragment 1 encoding five SNP variations was further analyzed by constructing deletion derivatives to identify a functional base substitution. The $3^{\prime}$ quarter of fragment 1 (+36 183 to 36474$)$ encoding rs6982502 retained enhancement activities and an allelic difference. Although most of the enhancement activities of the fragment were lost by further $3^{\prime}$ deletion, activity differed in the remaining sequence $(+36184$ to $36246)$ upon nucleotide substitution with rs6982502 (Fig. 5B). Therefore, we speculated that rs6982502 was a principal candidate for functional variation in the $25 \mathrm{~kb}$
LD block, although obvious disruption of binding motifs for transcription factors by the SNP was not predicted through a database search using MatInspector Software (Genomatix; http://www.genomatix.de/index.html).

\section{TRIB1 SNP was associated with NAFLD diagnosed by ultrasonography}

We assessed the effects of the candidate functional SNPs, rs6982502 and rs2980867, as well as the initially identified tag-SNP, rs17321515, on NAFLD in two populations to determine whether or not TRIB1 affects hepatic lipid accumulation in humans. The rates of ultrasonographically diagnosed NAFLD in populations 1 and 2 were 34.7 and $28.8 \%$ respectively. The genotype frequencies of the three SNPs conformed to Hardy-Weinberg predictions in these populations (Table 2). When age, sex, BMI, and clinical history of diabetes were the covariates, the three SNPs became significantly associated with ultrasonographic NAFLD and plasma TG in both populations (Table 2). The minor allele of rs6982502, C, maximally increased the risk of NAFLD $\left(P=9.39 \times 10^{-7}\right.$; odds ratio,
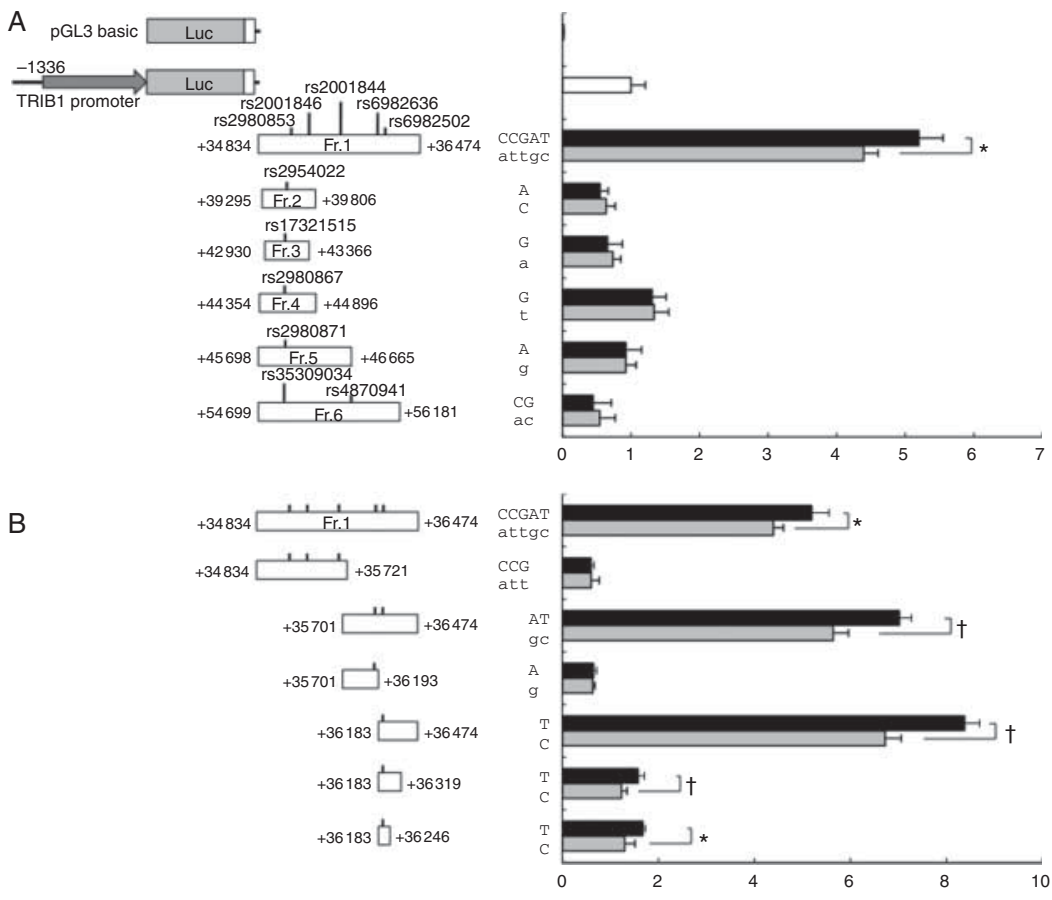

Figure 5

Reporter gene assays of human TRIB1 downstream sequences. Upstream sequence of TRIB1 gene from -1336 to -1 relative to ATG start codon was subcloned into pGL3 basic vector and used as parental vector (A). Six conservative fragments (Supplementary Fig. 4) were inserted at $3^{\prime}$ position of luciferase in parental vector. Relative positions of fragments are shown at both sides of diagram. Sequence variations in six fragments are indicated

by rs numbers. Major and minor alleles of SNPs are indicated by capital and lowercase letters respectively. Relative activities (firefly/Renilla light units) against parental vector are shown. Relative activities of deletion mutants of Fr.1 (B). ${ }^{*} P<0.05$ and ${ }^{\dagger} P<0.01$ (Student's $t$-test; among major and minor allele constructs)

Published by Bioscientifica Ltd. 
1.27, 95\% CI 1.17-1.39 (combined analysis)) and plasma TG level $\left(P=3.58 \times 10^{-6}\right)$ among the three SNPs (Table 2).

\section{Discussion}

We found that TRIB1 expression levels in the liver affected plasma and hepatic lipid levels in mouse models. Changes in plasma TG level were consistent with those of previous studies that included systemic knockout mice and hepatic overexpression via adeno-associated virus vector (AAV) (Burkhardt et al. 2010), but changes in hepatic lipid and glycogen levels were novel findings of this study. Therefore, we further examined the molecular mechanisms of TRIB1 in hepatic lipid accumulation using mouse models and genetic associations in a Japanese population that was ultrasonographically diagnosed with NAFLD. Hepatic transcriptome analysis showed that TRIB1 overexpression downregulated multiple genes that are involved in TG synthesis, gluconeogenesis, and glycogen synthesis. Burkhardt et al. (2010) found repressed levels of lipid oxidation transcripts (Cpt1a, Cpt2, and Acox1) in knockout mice, whereas Acox1 was repressed and Cpt1a expression was not affected in mice overexpressing TRIB1 in this study, suggesting that TRIB1 does not regulate expression levels of the genes that are involved in lipid oxidation. Modulation of the expression of multiple gene sets involved in nutrition metabolisms suggested that TRIB1 affects transcription factors or signaling molecules based on its biochemical features.

The expression of TRIB1 modulated the hepatic protein levels of all potential targets studied. Many studies have implicated CEBPA and СЕВPB in hepatic lipid biosynthesis (Wang et al. 1995, Lee et al. 1997, Matsusue et al. 2004, Qiao et al. 2006, Rahman et al. 2007, Schroeder-Gloeckler et al. 2007). Constituents of the MAPK pathway have also been implicated in steatohepatitis (Schattenberg et al. 2006). In addition to these, MLXIPL protein levels in the liver injected with adenovirus vectors suggested that MLXIPL regulates the TRIB1-induced modulation of hepatic lipid storage. Molecular interaction studies showed that MLXIPL is a novel target protein downregulated by TRIB1. MLXIPL is a glucose sensor that is involved in hepatic liponeogenesis (Uyeda \& Repa 2006). The SNPs of MLXIPL are closely associated with human plasma TG (Teslovich et al. 2010) and knockout mice are resistant to steatohepatitis (Dentin et al. 2006). Activated and nuclear translocated MLXIPL binds to carbohydrate-responsive element in lipogenic genes and upregulates the transcription of Pklr, Acc1, Fasn, and Mlxipl itself (Dentin et al. 2006, Denechaud http://jme.endocrinology-journals.org DOI: 10.1530/JME-13-0243
() 2014 Society for Endocrinology Printed in Great Britain
Published by Bioscientifica Ltd 
et al. 2008), which were downregulated by TRIB1 overexpression in this study, supporting the notion that TRIB1 modulates MLXIPL control of lipogenesis.

This study also found that TRIB1 negatively regulates hepatic glycogen storage. Insulin signals are thought to comprise a principal regulator of glycogen synthesis; glycogen synthesis was downregulated while the gene set for the insulin signaling pathway was upregulated. Furthermore, TRIB1 expression downregulated the gene set for gluconeogenesis. These results resembled the changes in glycogen storage caused by the genetic disruption of Cebpa in mice, which results in decreased hepatic glycogen and gluconeogenesis (Bezy et al. 2007, Wang et al. 2009). These facts indicated that enhanced CEBPA decay probably mediated glycogen exhaustion and low plasma glucose in mice overexpressing TRIB1.

Previous studies have identified molecular interaction between TRIB1 and NFkB p65, which enhances inflammation in adipose tissue (Ostertag et al. 2010). This study also found that TRIB1 overexpression significantly increased, whereas knockdown decreased levels of p65 protein. The overexpression of TRIB1 also enhanced mRNA levels of the gene set for cytokine-cytokine receptor interaction (Supplementary Table 2A). Leukocyte infiltration on day 8 might have resulted from activation of the NFkB pathway. Hepatic inflammation is thought to be a major contributor to the progression from simple steatosis to non-alcoholic steatohepatitis (NASH; Vanni et al. 2010). Insulin-resistant adipose tissue is thought to be the principal pathogenic source of adipokines and cytokines that are involved in hepatic inflammation. Further studies using conditional knockout mice are required to determine whether or not TRIB1 is involved in the pathogenesis of NASH.

Implication of TRIB1 in apoptosis for leukemogenesis is under dispute. Gilby et al. (2010) showed that TRIB1 enhanced apoptosis of leukemic cell line through suppression of JNK-Bcl-2 pathway. Yokoyama et al. (2010) showed that TRIB1 suppressed apoptosis through enhancement of Erk phosphorylation. TRIB1 overexpression in mouse liver reduced phosphorylation of JNK but did not affect on phosphorylation of Erk and enhanced the apoptosis of hepatocytes, which might have resulted in the massive elevation of plasma AST levels. Molecular mechanisms in cell type-specific regulation of MAPK pathway by TRIB1 should be resolved further.

Through functional screening in vitro, we identified a DNA fragment (Fr.1) in the downstream LD block of TRIB1 that had substantial enhancement activities in HepG2 cells but not in COS7 and 293 cells. The presence of an enhancer element in Fr.1 was supported by the ENCODE database showing methylation of lysine 4 of $\mathrm{H} 3$ histone (H3K4Me3), DNaseI hypersensitivity clusters and the ChIP-seq in HepG2 cells (Supplementary Fig. 4), whereas other cell lines show different H3K4Me3 peaks, suggesting cell-typespecific use of enhancer elements. The ChIP fragment generated by anti-p300 of HepG2 cells in the ENCODE database was identical to the minimum enhancer fragment (+36 183 to 36474$)$. rs6982502 localized in the fragment and modulated the enhancing activity. Base substitution of the minor allele of rs6982502, C, attenuated the enhancement activity to $80.2 \%$ of that of the major allele, T. Indeed, $-20 \%$ is a small effect, but our knockdown experiment $(20-40 \%$ reduction in production of the transcript) efficiently increased plasma and hepatic lipid, supporting the notion that rs6982502 is a candidate functional SNP in the LD block. Our SNP study of ultrasonographically diagnosed NAFLD showed that a significant association between rs6982502 and the minor allele increased risk for NAFLD 1.27-fold. The minor allele of rs6982502 showed a tight linkage $\left(D^{\prime}=0.985, r^{2}=0.713\right)$ with the risk allele of rs17321515 that the GWAS initially identified as a tag-SNP that increased plasma TG and LDL (Kathiresan et al. 2008). Relatively lower levels of TRIB1 expression due to the minor allele of rs6982502 might have resulted in increased levels of plasma lipid and progression to hepatic steatosis. While TRIB1 has not been significantly associated with NAFLD diagnosed by computed tomography (CT) (Romeo et al. 2008, Kawaguchi et al. 2012), the GWAS of plasma AST levels in Europe found a significant association with the SNP, rs2954021, which localized in the same LD block as rs17321515 (Chambers et al. 2011). A weak association between rs2954021 and hepatic steatosis was also identified (Chambers et al. 2011). Serum-free fatty acid arising from insulin-resistant adipose tissue and hepatic lipogenesis de novo increased by upregulated lipogenic gene expression are regarded as the principal pathogenetic pathways of NAFLD (Vanni et al. 2010). TRIB1 is considered a potential genetic factor of NAFLD because of its ability to modulate levels of lipogenic gene expression. Further genetic studies of various ethnic groups and haplotype effects are required to confirm the involvement of TRIB1 in the pathogenesis of NAFLD. The regulatory mechanisms of TRIB1 expression should also be revealed further to investigate regimen for the reduction of fat accumulation in liver. In our preliminary study, a highfat diet but not starvation induced the expression of Trib1 mRNA in mouse liver (Supplementary Fig. 5, see section on supplementary data given at the end of this article).

Published by Bioscientifica Ltd. 
In summary, chronic (SNP) or acute (adenoviral) modulation of TRIB1 expression affects hepatic lipid storage. Changes in hepatic lipid synthesis caused by TRIB1 were probably mediated, at least in part, by molecular interaction with the novel target, MLXIPL.

\section{Supplementary data}

This is linked to the online version of the paper at http://dx.doi.org/10.1530/ JME-13-0243.

\section{Declaration of interest}

The authors declare that there is no conflict of interest that could be perceived as prejudicing the impartiality of the research reported.

\section{Funding}

This study was supported by grants-in-aid from the Japanese Ministry of Education, Culture, Sports, Science, and Technology (numbers 22591001 and 21687021) and by a grant from the Kao Research Council for the Study of Healthcare Science (Tokyo, Japan).

\section{Acknowledgements}

The authors are grateful to Takashi Oyamada, Kayo Nagashima and Yukiko Ohashi for excellent technical assistance.

\section{References}

Bansal S, Buring JE, Rifai N, Mora S, Sacks FM \& Ridker PM 2007 Fasting compared with nonfasting triglycerides and risk of cardiovascular events in women. Journal of the American Medical Association 298 309-316. (doi:10.1001/jama.298.3.309)

Bezy O, Vernochet C, Gesta S, Farmer SR \& Kahn CR 2007 TRB3 blocks adipocyte differentiation through the inhibition of C/EBP $\beta$ transcriptional activity. Molecular and Cellular Biology 27 6818-6831. (doi:10. 1128/MCB.00375-07)

Burkhardt R, Toh SA, Lagor WR, Birkeland A, Levin M, Li X, Robblee M, Fedorov VD, Yamamoto M, Satoh T et al. 2010 Trib1 is a lipid- and myocardial infarction-associated gene that regulates hepatic lipogenesis and VLDL production in mice. Journal of Clinical Investigation 120 4410-4414. (doi:10.1172/JCI44213)

Chambers JC, Zhang W, Sehmi J, Li X, Wass MN, Van der Harst P, Holm H, Sanna S, Kavousi M, Baumeister SE et al. 2011 Genome-wide association study identifies loci influencing concentrations of liver enzymes in plasma. Nature Genetics 43 1131-1138. (doi:10.1038/ng.970)

Denechaud PD, Bossard P, Lobaccaro JM, Millatt L, Staels B, Girard J \& Postic C 2008 ChREBP, but not LXRs, is required for the induction of glucose-regulated genes in mouse liver. Journal of Clinical Investigation 118 956-964. (doi:10.1172/JCI34314)

Dentin R, Benhamed F, Hainault I, Fauveau V, Foufelle F, Dyck JR, Girard J \& Postic C 2006 Liver-specific inhibition of ChREBP improves hepatic steatosis and insulin resistance in ob/ob mice. Diabetes 55 2159-2170. (doi:10.2337/db06-0200)

Du K, Herzig S, Kulkarni RN \& Montminy M 2003 TRB3: a tribbles homolog that inhibits Akt/PKB activation by insulin in liver. Science $\mathbf{3 0 0}$ 1574-1577. (doi:10.1126/science.1079817)
ENCODE Project Consortium, Myers RM, Stamatoyannopoulos J, Snyder M, Dunham I, Hardison RC, Bernstein BE, Gingeras TR, Kent WJ, Birney E et al. 2011 A user's guide to the encyclopedia of DNA elements (ENCODE). PLoS Biology 9 e1001046. (doi:10.1371/journal.pbio.1001046)

Fukasawa M, Ge Q, Wynn RM, Ishii S \& Uyeda K 2010 Coordinate regulation/localization of the carbohydrate responsive binding protein (ChREBP) by two nuclear export signal sites: discovery of a new leucinerich nuclear export signal site. Biochemical and Biophysical Research Communications 391 1166-1169. (doi:10.1016/j.bbrc.2009.11.115)

Gilby DC, Sung HY, Winship PR, Goodeve AC, Reilly JT \& Kiss-Toth E 2010 Tribbles- 1 and -2 are tumour suppressors, down-regulated in human acute myeloid leukaemia. Immunology Letters 130 115-124. (doi:10.1016/j.imlet.2009.12.007)

Grosshans J \& Wieschaus EA 2000 A genetic link between morphogenesis and cell division during formation of the ventral furrow in Drosophila. Cell 101 523-531. (doi:10.1016/S0092-8674(00)80862-4)

Hegedus Z, Czibula A \& Kiss-Toth E 2007 Tribbles: a family of kinase-like proteins with potent signalling regulatory function. Cellular Signalling 19 238-250. (doi:10.1016/j.cellsig.2006.06.010)

Kathiresan S, Melander O, Guiducci C, Surti A, Burtt NP, Rieder MJ Cooper GM, Roos C, Voight BF, Havulinna AS et al. 2008 Six new loci associated with blood low-density lipoprotein cholesterol, highdensity lipoprotein cholesterol or triglycerides in humans. Nature Genetics 40189-40197. (doi:10.1038/ng.75)

Kawaguchi T, Sumida Y, Umemura A, Matsuo K, Takahashi M, Takamura T, Yasui K, Saibara T, Hashimoto E, Kawanaka M et al. 2012 Genetic polymorphisms of the human PNPLA3 gene are strongly associated with severity of non-alcoholic fatty liver disease in Japanese. PLOS ONE 7 e38322. (doi:10.1371/journal.pone.0038322)

Keeshan K, He Y, Wouters BJ, Shestova O, Xu L, Sai H, Rodriguez CG, Maillard I, Tobias JW, Valk P et al. 2006 Tribbles homolog 2 inactivates $\mathrm{C} / \mathrm{EBP} \alpha$ and causes acute myelogenous leukemia. Cancer Cell 10 401-411. (doi:10.1016/j.ccr.2006.09.012)

Law MR, Wald NJ \& Rudnicka AR 2003 Quantifying effect of statins on low density lipoprotein cholesterol, ischaemic heart disease, and stroke: systematic review and meta-analysis. BMJ 326 1423. (doi:10.1136/ bmj.326.7404.1423)

Lee YH, Sauer B, Johnson PF \& Gonzalez FJ 1997 Disruption of the c/ebp $\alpha$ gene in adult mouse liver. Molecular and Cellular Biology 17 6014-6022.

Lewington S, Whitlock G, Clarke R, Sherliker P, Emberson J, Halsey J, Qizilbash N, Peto R \& Collins R 2007 Blood cholesterol and vascular mortality by age, sex, and blood pressure: a meta-analysis of individual data from 61 prospective studies with 55,000 vascular deaths. Lancet 370 1829-1839. (doi:10.1016/S0140-6736(07)61778-4)

Li MV, Chang B, Imamura M, Poungvarin N \& Chan L 2006 Glucosedependent transcriptional regulation by an evolutionarily conserved glucose-sensing module. Diabetes 55 1179-1189. (doi:10.2337/db05-0822)

de Luis O, Valero MC \& Jurado LA 2000 WBSCR14, a putative transcription factor gene deleted in Williams-Beuren syndrome: complete characterisation of the human gene and the mouse ortholog. European Journal of Human Genetics 8 215-222. (doi:10.1038/sj.ejhg.5200435)

Matsusue K, Gavrilova O, Lambert G, Brewer HB Jr, Ward JM, Inoue Y, LeRoith D \& Gonzalez FJ 2004 Hepatic CCAAT/enhancer binding protein $\alpha$ mediates induction of lipogenesis and regulation of glucose homeostasis in leptin-deficient mice. Molecular Endocrinology 18 2751-2764. (doi:10.1210/me.2004-0213)

Nakayama K, Bayasgalan T, Yamanaka K, Kumada M, Gotoh T, Utsumi N Yanagisawa Y, Okayama M, Kajii E, Ishibashi S et al. 2009 Large scale replication analysis of loci associated with lipid concentrations in a Japanese population. Journal of Medical Genetics 46 370-374. (doi:10.1136/jmg.2008.064063)

Nordestgaard BG, Benn M, Schnohr P \& Tybjaerg-Hansen A 2007 Nonfasting triglycerides and risk of myocardial infarction, ischemic heart disease, and death in men and women. Journal of the American Medical Association 298 299-308. (doi:10.1001/jama.298.3.299) 
Ohoka N, Yoshii S, Hattori T, Onozaki K \& Hayashi H 2005 TRB3, a novel ER stress-inducible gene, is induced via ATF4-CHOP pathway and is involved in cell death. EMBO Journal 24 1243-1255. (doi:10.1038/sj.emboj.7600596)

Ostertag A, Jones A, Rose AJ, Liebert M, Kleinsorg S, Reimann A, Vegiopoulos A, Diaz MB, Strzoda D, Yamamoto M et al. 2010 Control of adipose tissue inflammation through TRB1. Diabetes 59 1991-2000. (doi:10.2337/db09-1537)

Qi L, Heredia JE, Altarejos JY, Screaton R, Goebel N, Niessen S, Macleod IX, Liew CW, Kulkarni RN, Bain J et al. 2006 TRB3 links the E3 ubiquitin ligase COP1 to lipid metabolism. Science 312 1763-1766. (doi:10.1126/ science.1123374)

Qiao L, MacLean PS, You H, Schaack J \& Shao J 2006 Knocking down liver ccaat/enhancer-binding protein $\alpha$ by adenovirus-transduced silent interfering ribonucleic acid improves hepatic gluconeogenesis and lipid homeostasis in db/db mice. Endocrinology 147 3060-3069. (doi:10.1210/en.2005-1507)

Rahman SM, Schroeder-Gloeckler JM, Janssen RC, Jiang H, Qadri I, Maclean KN \& Friedman JE 2007 CCAAT/enhancing binding protein $\beta$ deletion in mice attenuates inflammation, endoplasmic reticulum stress, and lipid accumulation in diet-induced nonalcoholic steatohepatitis. Hepatology 45 1108-1117. (doi:10.1002/hep.21614)

Romeo S, Kozlitina J, Xing C, Pertsemlidis A, Cox D, Pennacchio LA, Boerwinkle E, Cohen JC \& Hobbs HH 2008 Genetic variation in PNPLA3 confers susceptibility to nonalcoholic fatty liver disease. Nature Genetics 40 1461-1465. (doi:10.1038/ng.257)

Schattenberg JM, Singh R, Wang Y, Lefkowitch JH, Rigoli RM, Scherer PE \& Czaja MJ 2006 JNK1 but not JNK2 promotes the development of steatohepatitis in mice. Hepatology 43 163-172. (doi:10.1002/hep.20999)

Schroeder-Gloeckler JM, Rahman SM, Janssen RC, Qiao L, Shao J, Roper M, Fischer SJ, Lowe E, Orlicky DJ, McManaman JL et al. 2007 CCAAT/ enhancer-binding protein $\beta$ deletion reduces adiposity, hepatic steatosis, and diabetes in Lepr $(\mathrm{db} / \mathrm{db})$ mice. Journal of Biological Chemistry 282 15717-15729. (doi:10.1074/jbc.M701329200)
Sung HY, Francis SE, Crossman DC \& Kiss-Toth E 2006 Regulation of expression and signalling modulator function of mammalian tribbles is cell-type specific. Immunology Letters 104 171-177. (doi:10.1016/ j.imlet.2005.11.010)

Takahashi Y, Ohoka N, Hayashi H \& Sato R 2008 TRB3 suppresses adipocyte differentiation by negatively regulating PPAR $\gamma$ transcriptional activity. Journal of Lipid Research 49 880-892. (doi:10.1194/jlr.M700545-JLR200)

Teslovich TM, Musunuru K, Smith AV, Edmondson AC, Stylianou IM, Koseki M, Pirruccello JP, Ripatti S, Chasman DI, Willer CJ et al. 2010 Biological, clinical and population relevance of 95 loci for blood lipids. Nature 466 707-713. (doi:10.1038/nature09270)

Uyeda K \& Repa JJ 2006 Carbohydrate response element binding protein, ChREBP, a transcription factor coupling hepatic glucose utilization and lipid synthesis. Cell Metabolism 4 107-110. (doi:10.1016/j.cmet.2006. 06.008)

Vanni E, Bugianesi E, Kotronen A, De Minicis S, Yki-Järvinen H \& SvegliatiBaroni G 2010 From the metabolic syndrome to NAFLD or vice versa? Digestive and Liver Disease 42 320-330. (doi:10.1016/j.dld.2010.01.016)

Wang ND, Finegold MJ, Bradley A, Ou CN, Abdelsayed SV, Wilde MD, Taylor LR, Wilson DR \& Darlington GJ 1995 Impaired energy homeostasis in $\mathrm{C} / \mathrm{EBP} \alpha$ knockout mice. Science 269 1108-1112. (doi:10.1126/science.7652557)

Wang YG, Shi M, Wang T, Shi T, Wei J, Wang N \& Chen XM 2009 Signal transduction mechanism of TRB3 in rats with non-alcoholic fatty liver disease. World Journal of Gastroenterology 15 2329-2335. (doi:10.3748/ wjg.15.2329)

Yokoyama T \& Nakamura T 2011 Tribbles in disease: signaling pathways important for cellular function and neoplastic transformation. Cancer Science 102 1115-1122. (doi:10.1111/j.1349-7006.2011.01914.x)

Yokoyama T, Kanno Y, Yamazaki Y, Takahara T, Miyata S \& Nakamura T 2010 Trib1 links the MEK1/ERK pathway in myeloid leukemogenesis. Blood 116 2768-2775. (doi:10.1182/blood-2009-10-246264)

Received in final form 6 December 2013

Accepted 2 January 2014

Accepted Preprint published online 3 January 2014
C 2014 Society for Endocrinology Printed in Great Britain 